\title{
Carbon Nanotube-Epoxy Nanocomposites: Correlation and Integration of Dynamic Impedance, Dielectric, and Mechanical Analyses
}

\author{
O. Moudam, ${ }^{1}$ T. Andrews, ${ }^{1}$ C. Lekakou, ${ }^{1}$ J. F. Watts, ${ }^{1}$ and G. Reed $^{2}$ \\ ${ }^{1}$ Division of Mechanical, Medical and Aerospace Engineering, Faculty of Engineering and Physical Sciences, University of Surrey, \\ Guildford, Surrey GU2 7XH, UK \\ ${ }^{2}$ Department of Electronic Engineering, University of Surrey, Advanced Technology Institute (ATI), Faculty of Engineering and Physical \\ Sciences and Guildford, Surrey GU2 7XH, UK
}

Correspondence should be addressed to C. Lekakou; c.lekakou@surrey.ac.uk

Received 26 September 2012; Accepted 23 December 2012

Academic Editor: Jinquan Wei

Copyright (c) 2013 O. Moudam et al. This is an open access article distributed under the Creative Commons Attribution License, which permits unrestricted use, distribution, and reproduction in any medium, provided the original work is properly cited.

This study focuses on the characterization of MWNT-epoxy composites for different MWNT concentrations of $0-7$ wt $\%$ by correlating different dynamic analysis techniques, including DMA, impedance, and DEA. An optimum composition was established at $0.1 \mathrm{wt} \%$ MWNTs corresponding to the best MWNT dispersion which resulted in the formation of an optimum MWNT network. The addition of this low fraction of MWNTs in epoxy resulted in stiffening the molecular structure and suppressing certain molecular transitions, raising the dielectric constant especially in the low-to-medium frequency range, raising the electrical conductivity especially at the high frequencies, and increasing the electromagnetic shielding effectiveness. The $0.1 \%$ MWNT-epoxy nanocomposite switched the electromagnetic shielding behaviour from being a very effective absorber at low frequencies to being an effective reflector at high frequencies. Finally, the Nyquist plot derived from the dynamic impedance spectroscopy proved most useful at providing evidence of multiple size distribution of MWNT agglomerates.

\section{Introduction}

Epoxy resin is the polymer matrix used most often with reinforcing fibres for advanced composite applications and is widely employed as an insulation material in many electrical and electronic applications because of its excellent electrical and mechanical characteristics [1-5]. Resins of this class have good stiffness, specific strength, dimensional stability, and chemical resistance. They are usually mixed with appropriate fillers to enhance the electrical and mechanical properties showing considerable adhesion to the embedded fibres. Many attempts have been made to modify epoxy by adding either rubber particles $[6,7]$ or fillers $[8]$ to improve the matrixdominated composite properties. The addition of the former improves the fracture toughness of epoxy but decreases its modulus and strength, whilst the latter improves the modulus and strength of epoxy but decreases its fracture toughness. Nanofillers such as nanoparticulates, nanotubes, graphite nanofibres, grapheme, and other nanofibres $[9,10]$ blended with polymer composites have drawn much attention because they are expected to produce high-performance composites with enhanced properties, including improvements in toughness.

For this reason, carbon nanotubes (CNTs) have generated much interesting research since their discovery [11] in 1991. CNTs possess excellent electrical and mechanical [12-15], thermal [16], and magnetic properties [17] and chemical stability. Most particularly their nanocomposites with a high surface area of the CNT network are of low density, high strength, improved toughness, and electrically conductive [18].

Some of these properties have been exploited by the incorporation of nanomaterials into some form of matrix such as polymers. The initial preparation of carbon nanotube/polymer composite materials, which have been intensively investigated in the past few years, involved combining 


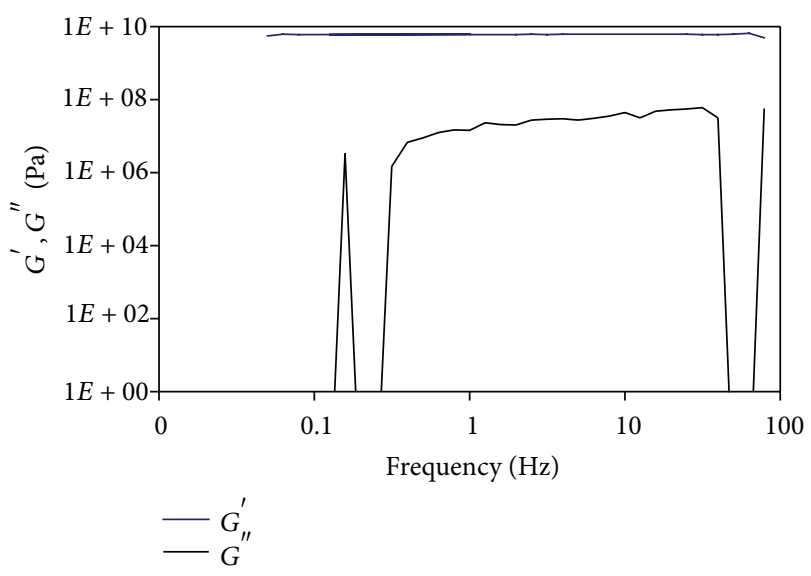

(a)

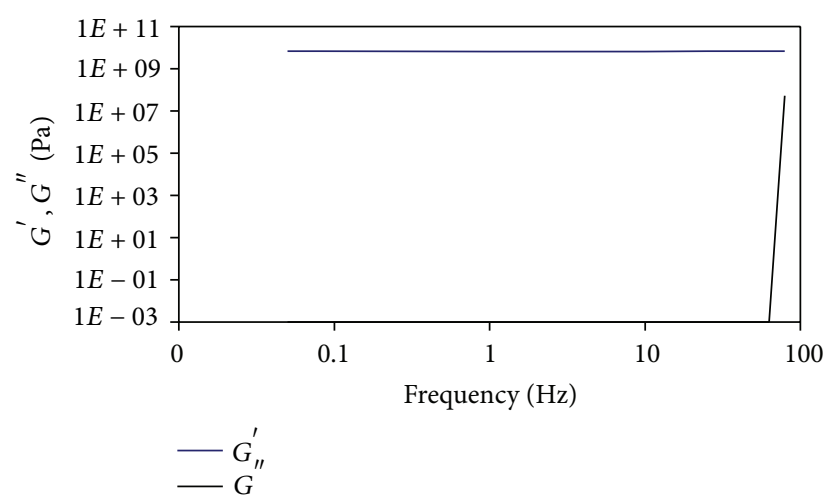

(b)

FIGURE 1: DMA: Elastic and viscous shear modulus as a function of frequency: (a) epoxy; (b) 0.1 wt\% MWNT-epoxy.

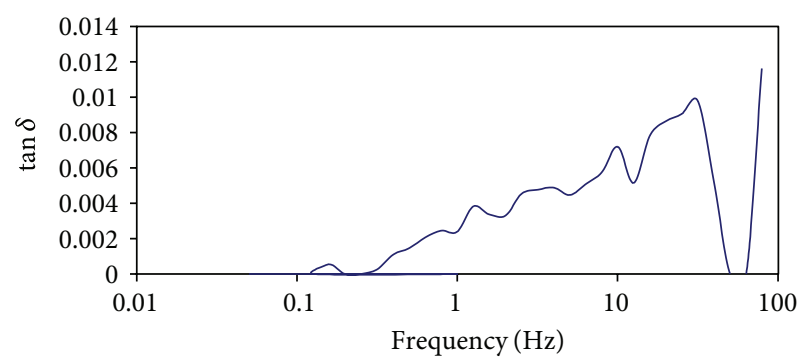

(a)

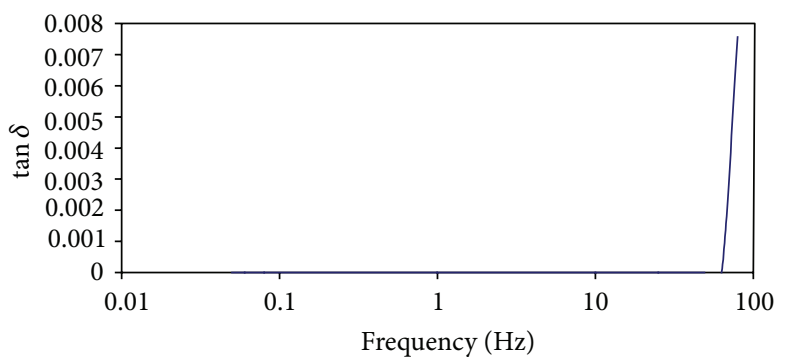

(b)

Figure 2: DMA: $\tan \delta$ as a function of frequency: (a) epoxy; (b) $0.1 \mathrm{wt} \%$ MWNT-epoxy.

CNTs with various polymer matrices, such as polyurethane $[19,20]$, polyamides $[21,22]$, polypyrrole $[23,24]$, polythiophene $[25,26]$, polysilsesquioxane $[27,28]$, polypropylene $[29,30]$, and epoxy $[31,32]$ to produce functional composite materials with the aim of improving their electrical and mechanical properties. Furthermore, these composites can have potential uses in aerospace applications [33], supercapacitors [34], sensors [35], actuators [36], luminescent and photovoltaic devices [37], electrostatic as well as conductive coatings in optical devices [37], and electromagnetic shielding [37].

Polymer-based nanocomposites derive their advanced properties from low filler volume fractions due to the high surface area to volume ratio of the nanosized particles and, in the case of CNTs, the high aspect ratio which favours network formation: optimal CNT loading in the matrix is a key parameter to developing a nanophased structure composite. A key issue in this area is the dispersion of nanotubes which tend to form aggregates. Various physical and chemical methodologies have been proposed to disentangle CNTs by wrapping them with long polymer chains of polymer additives or surfactants or by functionalizing them with groups with long organic tails that wrap around the nanotubes. Although such methods are very effective at dispersing the CNTs, the wrapping organic chains act as insulators at the CNT-CNT contacts and reduce the electrical and thermal conductivity of the network so that the resulting nanocomposite may have improved mechanical properties but low electrical and thermal conductivity [38]. Hence, dispersion is carried out by sonication and high shear mixing which may be difficult for viscous fluids, in which case an additional solvent may be used to aid dispersion [39]. Furthermore, multiwall carbon nanotubes (MWNTs) have been used in this study, which are easier to disperse than single-wall carbon nanotubes (SWNTs), behave as metallic due to their large diameter, and are presently of lower cost.

In general, there is a distinction between carbon nanotube-polymer composites with thermoplastic matrices versus such composites with thermoset matrices cured in situ during processing; there are several reasons for this distinction with the focus on two main factors: (a) the low viscosity of the prepolymers of thermoset matrices compared with the very high viscosity of thermoplastic polymer melts which generally involves different processing techniques for the mixing and processing of the two different classes of composites; (b) the high molecular weight of the starting thermoplastic polymer mixed with the CNTs which if well dispersed will be wrapped with long molecular chains at the contact points and form a composite of much lower electrical conductivity than a corresponding thermoset polymer composite with the matrix curing taking place after the CNT dispersion process in a low-molecular-weight 


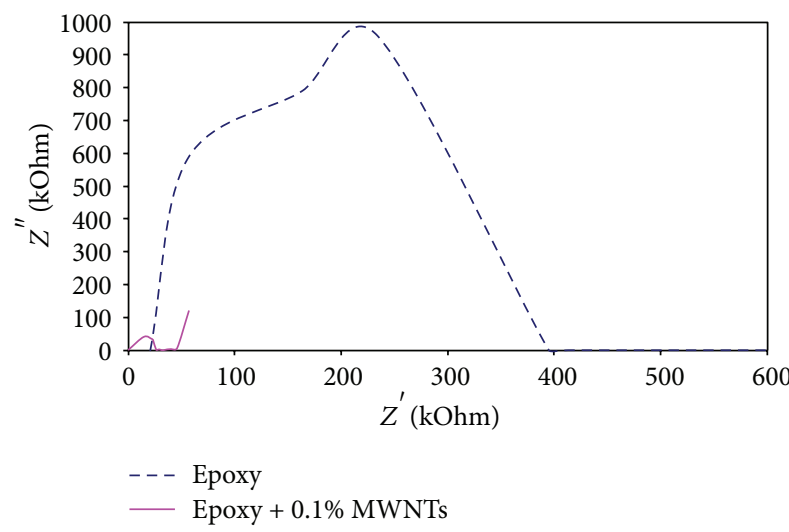

(a)

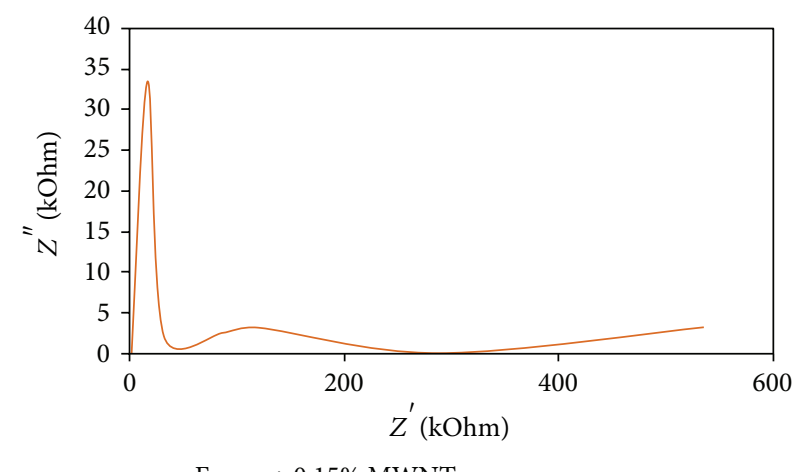

FIGURE 3: Impedance analysis: Nyquist plot for (a) epoxy and $0.1 \mathrm{wt} \%$ MWNT-epoxy nanocomposite; (b) 0.15 wt\% MWNT-epoxy nanocomposite. Frequency range: from $100 \mathrm{kHz}$ to $12 \mathrm{~Hz}$.

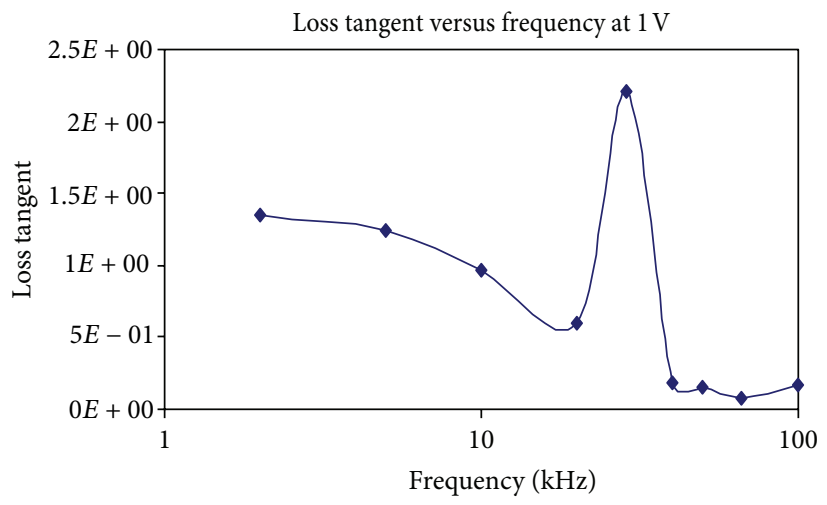

(a)

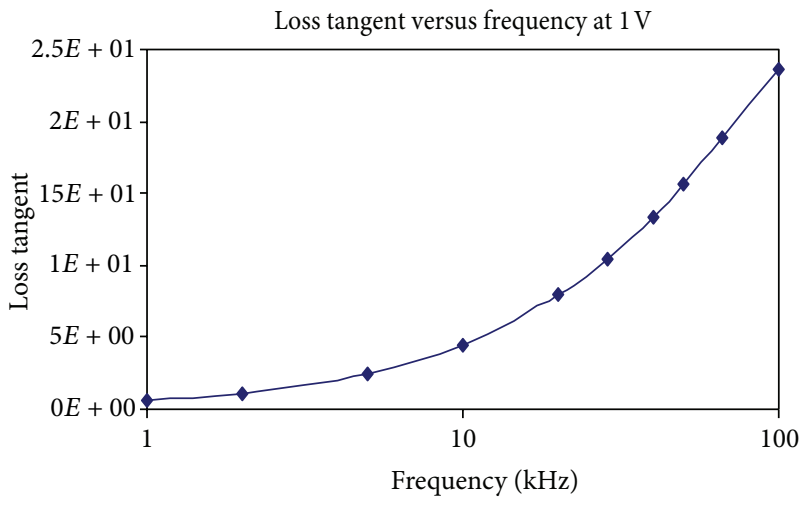

(b)

FIGURE 4: Impedance analysis: loss tangent versus frequency plot for (a) epoxy, (b) $0.1 \mathrm{wt} \%$ MWNT-epoxy nanocomposite.

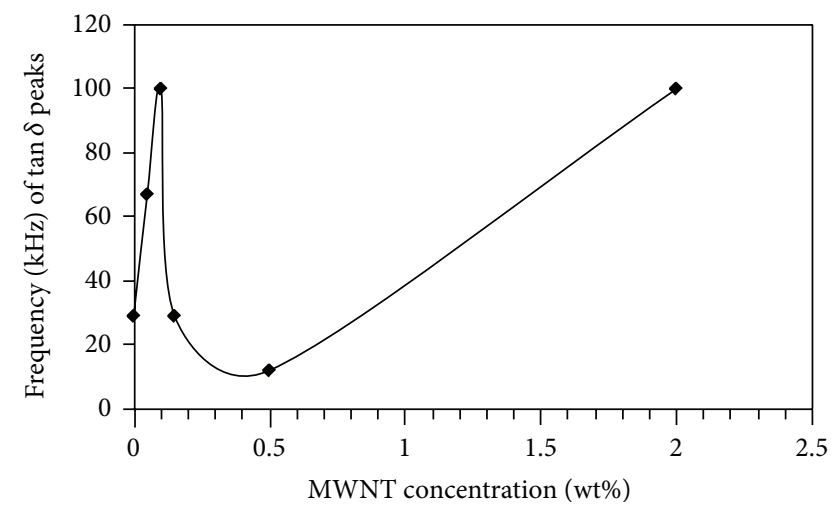

FIGURE 5: Impedance analysis: plot of the transition frequencies as a function of the MWNT concentration in the nanocomposite, including a pure epoxy specimen ( $0 \%$ concentration).

prepolymer or monomer reactant mixture. This has been demonstrated in extensive studies by Rebord et al. [38] of
MWNT-thermoplastic polyurethane and MWNT-thermoset polyurethane composites.

Carbon black has been used traditionally to increase the conductivity of polymer composites, where it has been reported [40] that an electrical conductivity $\sigma=0.26 \mathrm{~S} / \mathrm{cm}$ can be reached with carbon black loadings in epoxy of over $2 \mathrm{vol} \%$ after just ordinary mixing and of $0.6 \mathrm{vol} \%$ after shear mixing. Sandler et al. [41] manufactured MWNT-epoxy composites by dispersing the MWNTs in Araldite LY 556 under shear mixing of $2000 \mathrm{rpm}$ for $1 \mathrm{~h}$ at room temperature and for $1 \mathrm{~h}$ at dry ice reduced temperatures to increase the viscous shear forces. The electrical conductivity increased from $\sigma=2 \times 10^{-11} \mathrm{~S} / \mathrm{cm}$ for epoxy at $1 \mathrm{~Hz}$ to $\sigma=4 \times 10^{-10} \mathrm{~S} / \mathrm{cm}$ at the observed MWNT percolation limit of $0.0025 \mathrm{wt} \%$, continuing to $3 \times 10^{-4} \mathrm{~S} / \mathrm{cm}$ for $0.1 \mathrm{wt} \%$ MWNTs and to $2 \mathrm{~S} / \mathrm{cm}$ for $1 \mathrm{wt} \%$ MWNTs. It was interesting to observe the conductivity of these nanocomposites as a function of $\mathrm{AC}$ frequency, where pure epoxy and MWNT-epoxy composites at the percolation limit exhibited conductivity increasing with frequency, whereas higher MWNT contents above $0.005 \mathrm{wt} \%$ had constant electrical conductivity in the range of $1-10^{5} \mathrm{~Hz}$. 


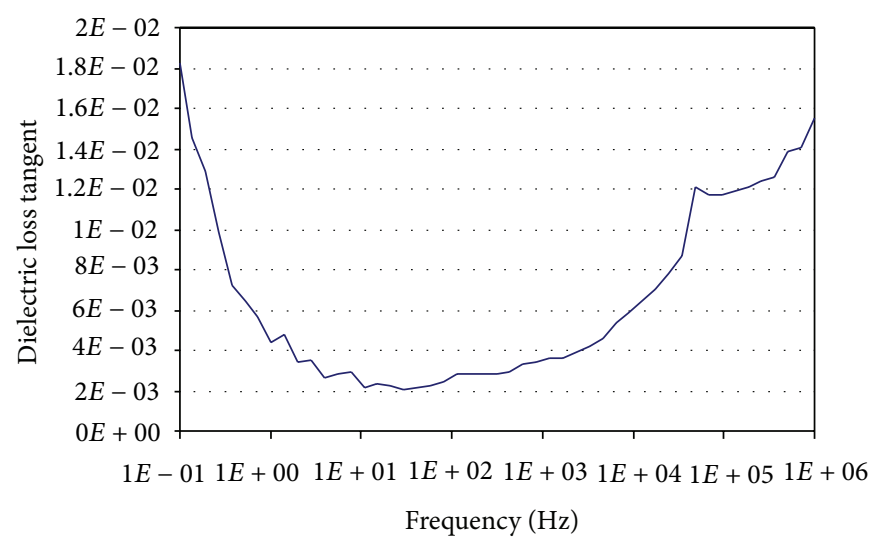

(a)

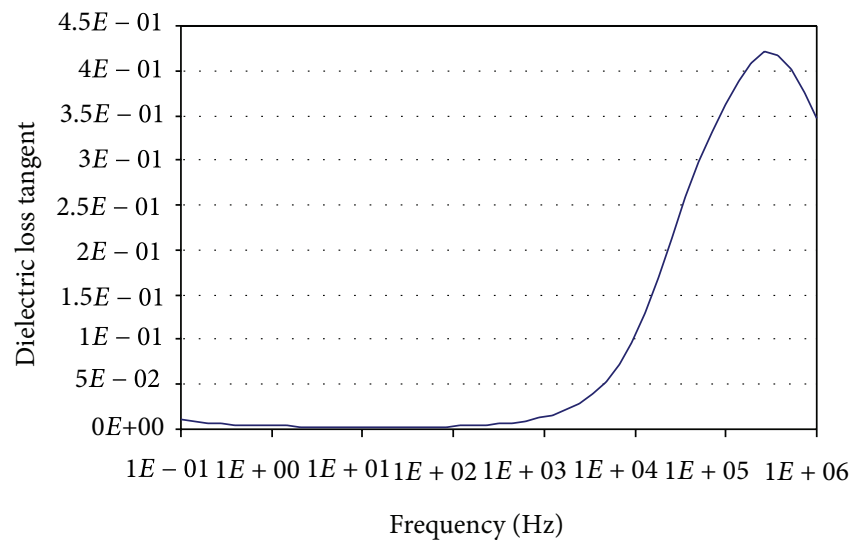

(b)

Figure 6: DEA: $\tan \delta$ spectrum as a function of frequency $(0.1 \mathrm{~Hz}$ to $1 \mathrm{MHz})$ : (a) epoxy; (b) $0.1 \mathrm{wt} \%$ MWNT-epoxy nanocomposite.

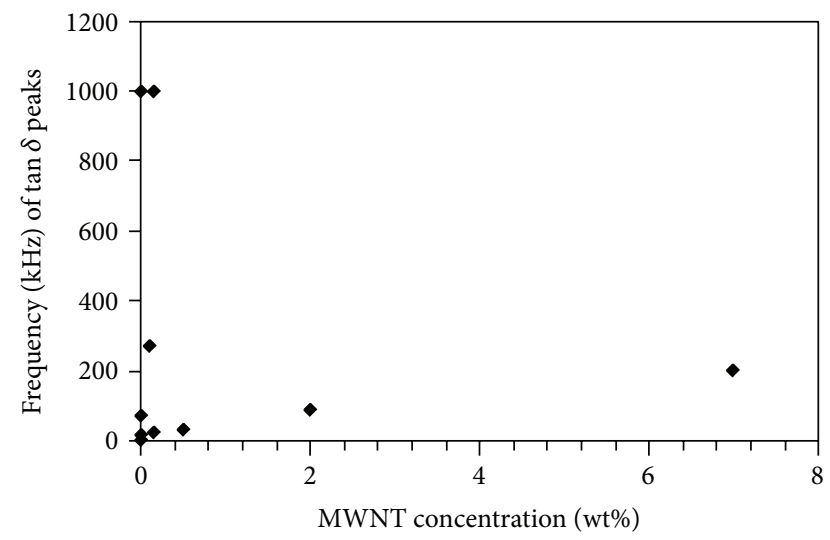

FIGURE 7: DEA: plot of the transition frequencies as a function of the MWNT concentration in the nanocomposite, including a pure epoxy specimen ( $0 \%$ concentration).

Chang et al. [42] fabricated MWNT- (Baytubes C150P)-epoxy (Araldite LY564 + Aradur HY 2964) nanocomposites of MWNTs by dispersing the MWNTs in a vacuum dissolver followed by 3-roll calendering to break the MWNT aggregates. They varied the MWNT content systematically in the range of $0.01-0.6 \mathrm{vol} \%$ where they found that in this range the nanocomposite obeyed a percolation-like power law with a theoretical percolation limit predicted from the extrapolation of the power law to be $0.02 \mathrm{vol} \%$ MWNT. A sharp rise in the measured conductivity was observed at 0.05 vol\% MWNTs $\left(\sigma=10^{-7} \mathrm{~S} / \mathrm{cm}\right)$ with a very slow conductivity rise above 0.1 vol\% MWNTs $\left(\sigma=10^{-6} \mathrm{~S} / \mathrm{cm}\right)$. Hence, in their experimental data the value of 0.05 vol\% MWNTs looked as their experimental percolation point.

Apart from these studies, few papers have been published on the electromagnetic properties of these types of carbon nanotube nanocomposites. In general, electromagnetic interference (EMI) shielding may be achieved by three mechanisms [43]: reflection loss which is a function of $\sigma_{r} / \mu_{r}\left(\sigma_{r}\right.$ : electrical conductivity relative to that of copper; $\mu_{r}$ : magnetic permeability relative to that of free space), absorption loss which is a function of $\sigma_{r} \mu_{r}$, and multiple reflection loss at interfaces, the latter maximized in nanocomposites of large area of interfaces close to each other. Li et al. [44] investigated the EMI properties of single wall-nanotube (SWNT) nanocomposites and they found that SWNT-epoxy has high EMI shielding effectiveness (SE) at low frequencies 


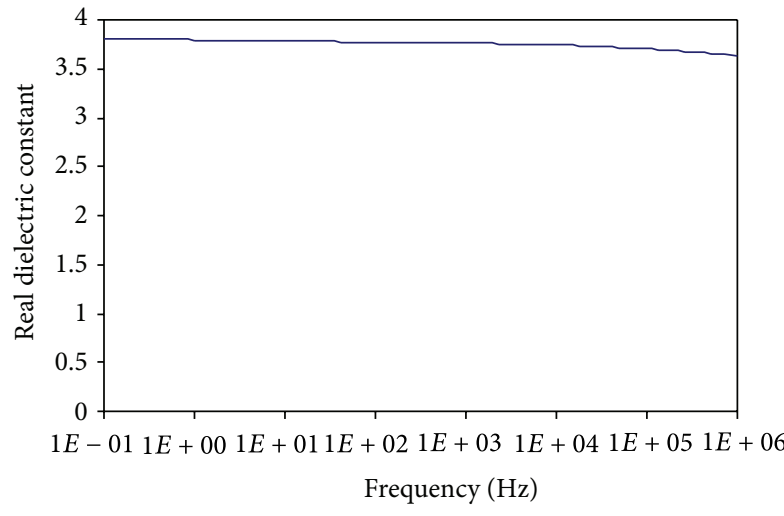

(a)

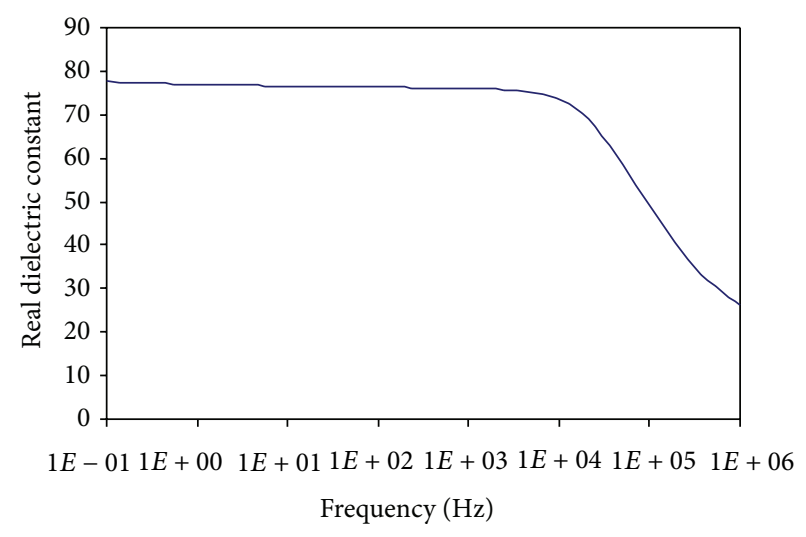

(b)

Figure 8: DEA: dielectric constant (real part) as a function of frequency (0.1 Hz to $1 \mathrm{MHz}$ ): (a) epoxy; (b) $0.1 \mathrm{wt} \%$ MWNT-epoxy nanocomposite.

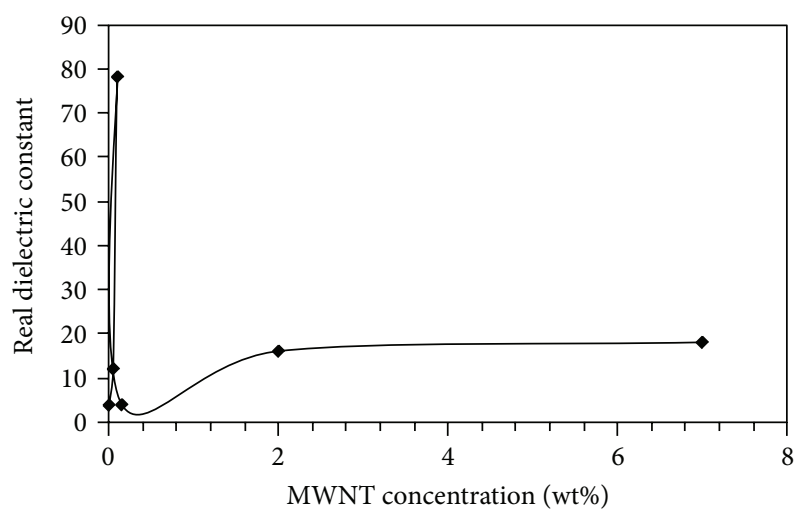

Figure 9: DEA: Plot of the dielectric constant (real part) at $0.1 \mathrm{~Hz}$ as a function of the MWNT concentration in the nanocomposite, including a pure epoxy specimen ( $0 \%$ concentration).

but much lower SE at high frequencies and the EMI SE was due mainly to reflection dominated by dc conductivity. Yeh et al. [45] found that the most effective processing route to use high MWNT contents in epoxy for EMI SE, up to $2 \mathrm{wt} \%$ MWNTs, was by spreading MWNTs onto epoxy surfaces and creating MWNT interlayers rather than mixing in epoxy, due to MWNT agglomeration problems in bulk MWNT-epoxy composites.

Dynamic dielectric analysis (DEA) is often used to monitor curing in polymer matrices but not so much for the characterization of polymer composites. Guo et al. [46] measured the dielectric constant of MWNT-epoxy composites as a function of frequency for different MWNT contents in the range of $0-4.2 \mathrm{wt} \%$ : they measured the highest dielectric constant $\varepsilon_{r}=14$ at $1 \mathrm{~Hz}$ for the $2.2 \mathrm{wt} \%$ MWNT specimen, while $\varepsilon_{r}$ fell with increasing frequency. $\mathrm{Cu}$ - and Ag-filled MWNTepoxy composites displayed higher $\varepsilon_{r}$ values, $\varepsilon_{r, \mathrm{Cu}-\mathrm{MWNT}}=$ 80 and $\varepsilon_{r, \mathrm{Ag}-\mathrm{MWNT}}=300$ for $3.2 \mathrm{wt} \%$ and $1.1 \mathrm{wt} \%$, respectively, and large $\varepsilon_{r}$ plateau in the range of $1-10 \mathrm{~Hz}$ and $1-1000 \mathrm{~Hz}$, respectively, before $\varepsilon_{r}$ fell with increasing frequency.
It has been shown that the addition of MWNTs in epoxy may improve various mechanical properties if the MWNTs are well dispersed, the fracture toughness by $60 \%$, the modulus and flexural strength by $10 \%$ at $0.5 \mathrm{wt} \%$ MWNT loading [47]. Functionalisation of MWNTs with polymer chains, for example, MWNT-PEI functionalized [48], results in better MWNT dispersion in epoxy and better mechanical properties but lower electrical conductivity [47], as expected due to the insulating nature of the MWNT wrapping polymer chains.

In this work, MWNT-epoxy matrix composites were manufactured at different MWNT concentrations, ranging from 0 to $7 \mathrm{wt} \%$, with the focus on determining an optimum concentration. Dynamic dielectric (DEA), impedance, and mechanical analyses (DMA) were performed to evaluate the electrical, electromagnetic, and mechanical performance. Most interesting, these techniques were investigated in combination to elucidate the transition spectrum of the material in broadband. This is particularly interesting as the various techniques or available equipment cover different regions of the frequency range. Finally, the effectiveness of the electromagnetic shielding of these materials was estimated over the tested frequency range.

\section{Materials and Experimental Techniques}

The CNTs used in this study were Elicarb multiwall carbon nanotubes (MWNTs) from Thomas Swan Ltd. Their specifications, as provided by their manufacturer, include 10$30 \mathrm{~nm}$ outer diameter, 3-10 $\mathrm{nm}$ inner diameter, an average length of tens of microns, and $>92 \%$ purity. Furthermore, the product datasheet provided by the manufacturer includes the raman spectrum at $514 \mathrm{~nm}$ excitation: in this the $D$ and $G$ peaks can be seen, related to disorder-induced $D$ band and crystalline graphitic structures, respectively, with an intensity ratio $I_{D} / I_{G}=0.96$. Gromov et al. [49] characterised the same Elicarb MWNTs (denoted as "pristine" in their paper [49] before being functionalised): their XPS analysis [49] yielded a surface atomic composition of 99.52 at\% C and 


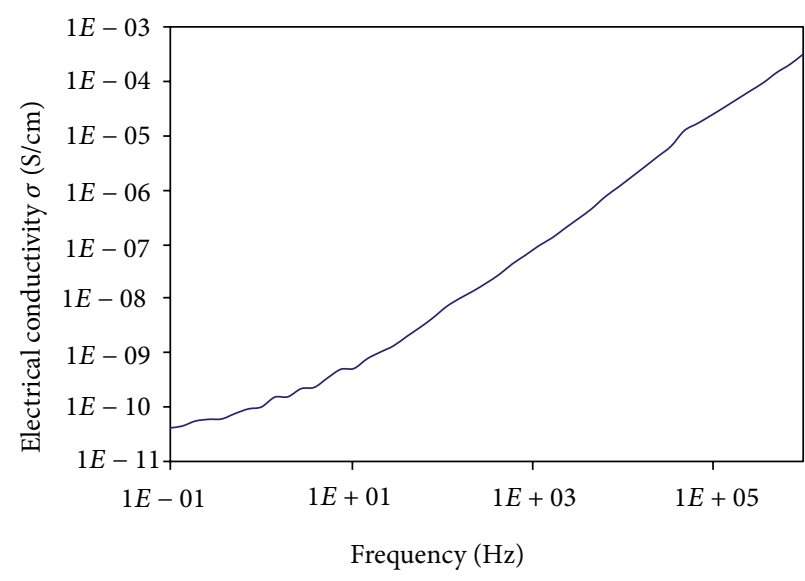

(a)

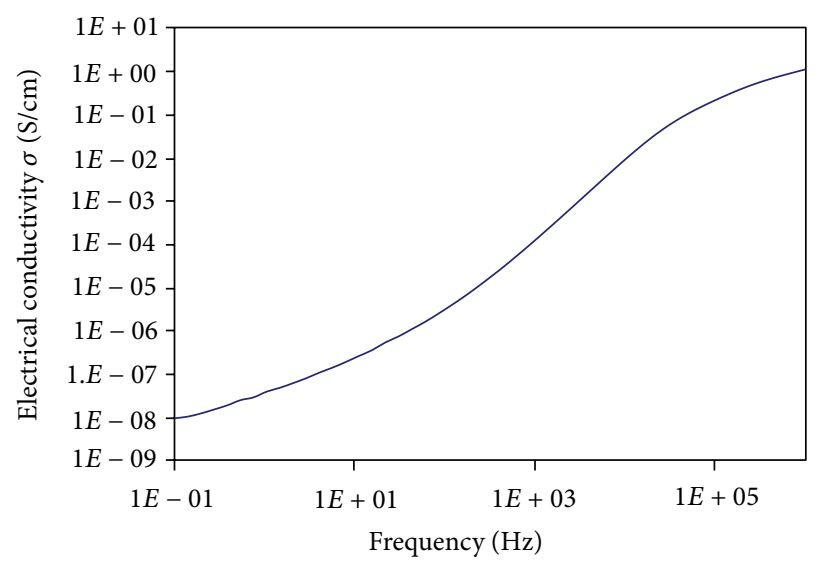

(b)

FIGURE 10: DEA: electrical conductivity as a function of frequency $(0.1 \mathrm{~Hz}$ to $1 \mathrm{MHz})$ : (a) epoxy; (b) 0.1 wt\% MWNT-epoxy nanocomposite.

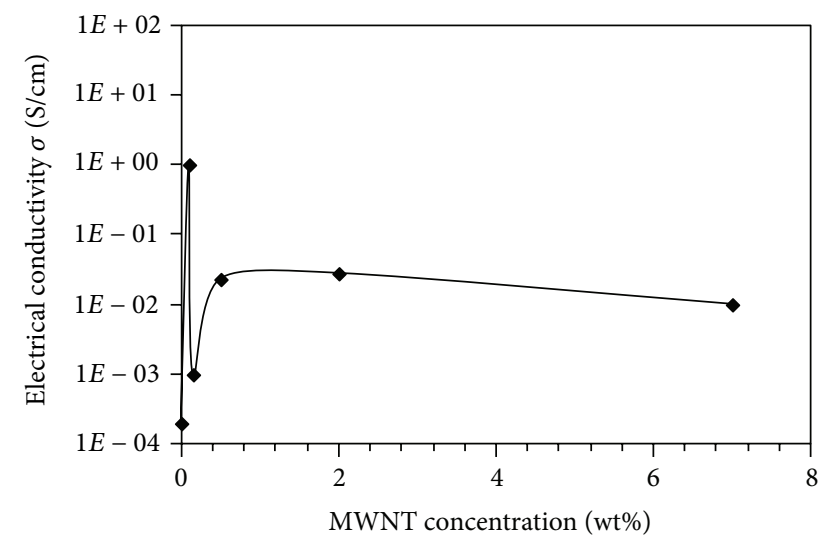

FIGURE 11: DEA: plot of the electrical conductivity at $1 \mathrm{MHz}$ as a function of the MWNT concentration in the nanocomposite, including a pure epoxy specimen ( $0 \%$ concentration).

0.48 at\% O; FTIR spectra of these "pristine" Elicarb MWNTs [49] showed no $\mathrm{C}=\mathrm{O}$ and $-\mathrm{COO}-$ group peaks at 2100$2360 \mathrm{~cm}^{-1}$ [50], a very weak peak around $1700 \mathrm{~cm}^{-1}$ assigned to the $\mathrm{C}=\mathrm{O}$ stretching mode of the $-\mathrm{COOH}$ groups [50], and a main distinct peak at $1540 \mathrm{~cm}^{-1}$ related to the stretching mode of $\mathrm{C}=\mathrm{C}$ bonds [50] which are the main part of the CNT shell. The epoxy matrix comprised Araldite LY 564 and hardener HY2954 (from B\&K Resins Ltd.) in a ratio of 100 : 35 by weight. Composites of $0.05,0.1,0.15,0.5,2$, and $7 \mathrm{wt} \%$ MWNT in epoxy were fabricated for this study. The CNTs were dispersed in the epoxy via the aid of a low-viscosity solvent as optimised in our previous work [39, 51]. More specifically CNTs were dispersed in methanol and Araldite LY 564 first in an ultrasound bath for $60 \mathrm{~min}$ and afterwards in a shear mixer at $10000 \mathrm{rpm}$ for $60 \mathrm{~min}$. Thereafter, the methanol was let to evaporate at $55^{\circ} \mathrm{C}$. The hardener was then added and mixed, and the mixture was poured into the mould cavity and was left to cure at room temperature. Pure epoxy samples (without CNTs) were also fabricated and tested as reference samples.
Dynamic mechanical analysis (DMA) was performed in a Rheometrics RDA II in torsion mode at $20^{\circ} \mathrm{C}$ in the frequency range of $0.05 \mathrm{~Hz}$ to $79 \mathrm{~Hz}$. Impedance measurements, including inductance, capacitance, and resistance, were performed using an ISO-TECH LCR819 meter in the frequency range of $12 \mathrm{~Hz}$ to $100 \mathrm{kHz}$. Finally, dielectric analysis (DEA) was performed using an Alpha-A dielectric spectrometer (Novocontrol $\mathrm{GmbH}$ ) in the frequency range of $0.1 \mathrm{~Hz}$ to $1 \mathrm{MHz}$.

\section{Results}

As it will be presented in this section, the $0.1 \mathrm{wt} \%$ MWNTepoxy composition yielded the best properties. Hence, this will be the nanocomposite of focus in the presentation of all graphs related to the detailed discussion of the integration of dynamic impedance, dielectric (DEA), and mechanical (DMA) analyses. Figures $1(\mathrm{a})$ and 1(b) display the elastic shear modulus, $G^{\prime}$, and viscous shear modulus, $G^{\prime \prime}$, for the epoxy and $0.1 \mathrm{wt} \%$ MWNT-epoxy, respectively. Figures 2(a) and 2(b) present the DMA spectrum of $\tan \delta=G^{\prime \prime} / G^{\prime}$ as a function of frequency $(0.05-79 \mathrm{~Hz})$ for the epoxy and $0.1 \mathrm{wt} \%$ MWNT-epoxy, respectively. The DMA spectrum shows that the epoxy sample has a peak in $\tan \delta$ at $31.5 \mathrm{~Hz}$ and also the curve rises possibly for another peak after $63 \mathrm{~Hz}$. The $0.1 \%$ MWNT-epoxy nanocomposite shows an increase in $\tan \delta$ after $63 \mathrm{~Hz}$, continuing to the top frequency of $79 \mathrm{~Hz}$. The DMA results indicate a transition starting at $63 \mathrm{~Hz}$, common to both pure epoxy and MWNT-epoxy nanocomposite. Pure epoxy seems to have another transition peak at $31.5 \mathrm{~Hz}$, which seems to have been suppressed in the MWNT-epoxy nanocomposite, most probably because the CNT network stiffens the material and inhibits further molecular transition at $31.5 \mathrm{~Hz}$.

Dynamic impedance analysis involves the measurement of inductance, $L$, capacitance, $C$, and resistance, $R$. LCR results can be processed to determine impedance, $Z$, according to the equations:

$$
Z=Z^{\prime}+i Z^{\prime \prime}
$$




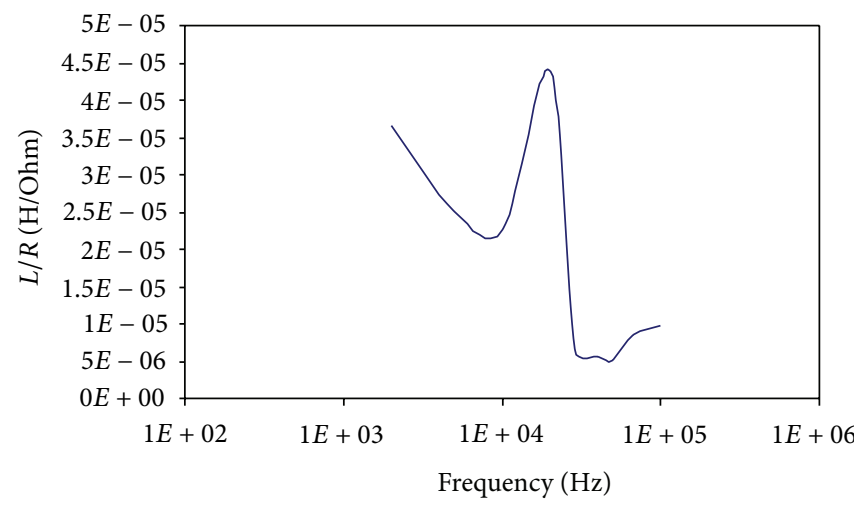

(a)

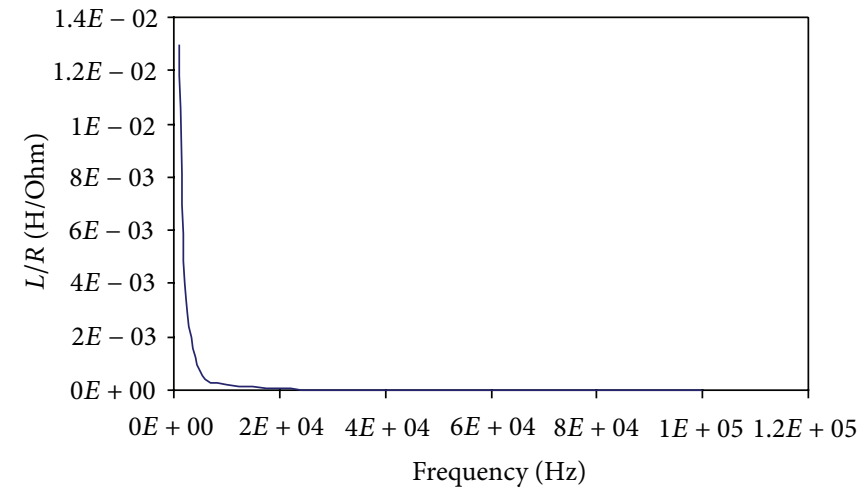

(b)

FIgURE 12: Measure of the absorption loss as a function of frequency: (a) epoxy; (b) $0.1 \mathrm{wt} \%$ MWNT-epoxy nanocomposite.

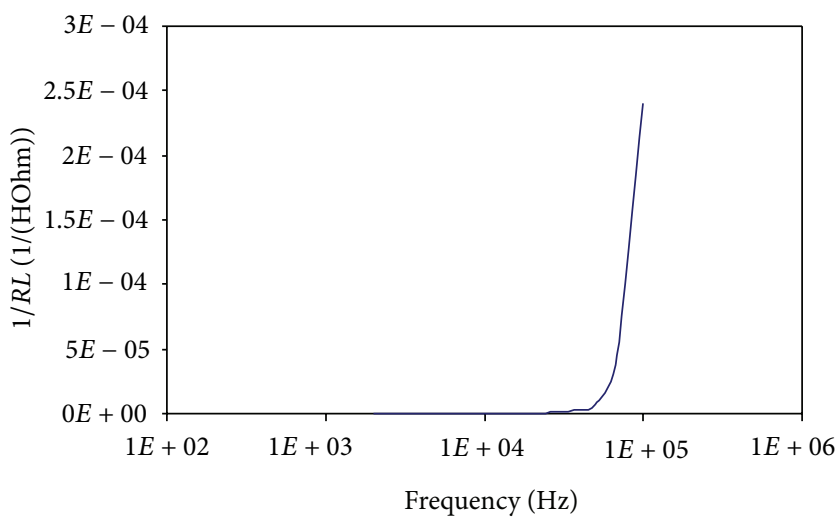

(a)

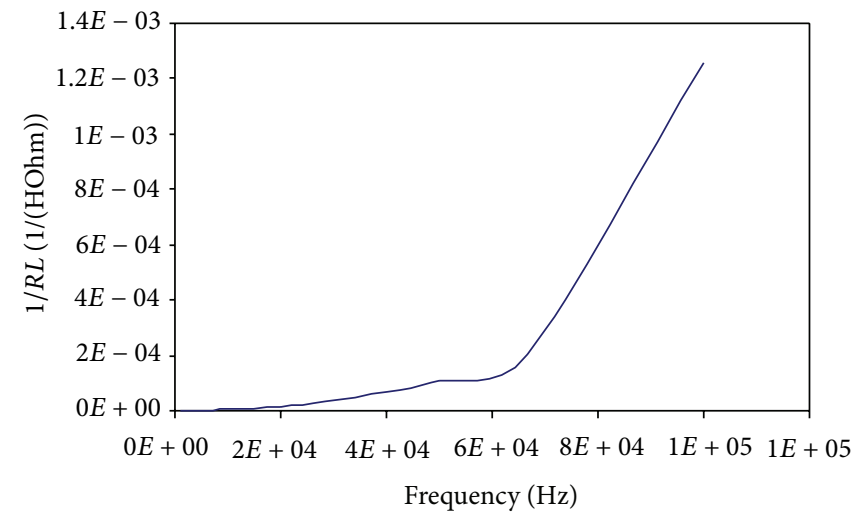

(b)

FIGURE 13: Measure of the reflection loss as a function of frequency: (a) epoxy; (b) $0.1 \mathrm{wt} \%$ MWNT-epoxy nanocomposite.

where $Z^{\prime}$ is the real part, representing the resistance, $R$. The imaginary part $Z^{\prime \prime}$ is reactance, $X$, which consists of two separate parts:

$$
Z^{\prime \prime}=X=\left|X_{C}\right|-\left|X_{I}\right|,
$$

$X_{C}$ is the capacitive reactance given by

$$
X_{C}=\frac{1}{i \omega C},
$$

$X_{I}$ is the inductive reactance given by

$$
X_{I}=i \omega L \text {, }
$$

where $C$ is the capacitance and $L$ is the inductance. The phase angle $\theta$ is the angle between the $Z$ vector and $Z^{\prime}$ and the loss angle $\delta$ is the angle between $Z^{\prime \prime}$ and the $Z$ vector, where the dielectric loss tangent $\tan \delta$ is given by the relation:

$$
\tan \delta=\frac{Z^{\prime}}{X_{c}}=\frac{R}{X_{c}} .
$$

Figure 3(a) presents the Nyquist plots of epoxy and $0.1 \mathrm{wt} \%$ MWNT-epoxy nanocomposite. The epoxy shows a large semicircle signifying that it acts as a resistor with a low frequency interface resistance of about $400 \mathrm{kOhm}$ at $28 \mathrm{kHz}$. The $0.1 \mathrm{wt} \%$ MWNT-epoxy nanocomposite has a smaller semicircle showing the lower resistance offered due to the presence of the network of well-dispersed, electrically conductive MWNTs. The low-frequency interface resistance of this CNT-epoxy nanocomposite is $30 \mathrm{kOhm}$ at $20 \mathrm{kHz}$. Below $20 \mathrm{kHz}$, there is a straight line at a phase angle $\theta=$ $84.5^{\circ}$, indicating the capacitance of the sample. Figure 3(b) presents the Nyquist plot of the $0.15 \mathrm{wt} \%$ MWNT-epoxy composite which presents two peaks attributed to insufficient MWNT dispersion: the first peak comes down to an interface resistance of $35 \mathrm{kOhm}$ at around $550 \mathrm{~Hz}$ and it is associated to the nanodispersed MWNTs; the second peak seems part of an extended semicircle indicating a size distribution of MWNT agglomerates yielding an overall interface resistance of $288 \mathrm{kOhm}$ at $300 \mathrm{~Hz}$. This is a clear indication that the concentration of $0.1 \mathrm{wt} \%$ MWNTs is the highest MWNT content that could be satisfactorily dispersed in this study following the experimental procedures described in Section 2.

Figure 4 displays the dielectric loss tangent of epoxy and MWNT-epoxy nanocomposite, respectively. In general, epoxy has relatively low loss angle, $\delta$, at high frequencies 
$\left(5-10^{\circ}\right)$, then $\delta$ rises to high losses during a transition at $29 \mathrm{kHz}$ and stabilises around $50^{\circ}$ at low frequencies. The $0.1 \mathrm{wt} \%$ MWNT-epoxy nanocomposite exhibits very low loss at low frequencies (where in fact the Nyquist diagram in Figure 3(a) shows capacitor behaviour) and rising losses at higher frequencies with $\delta=23^{\circ}$ at $100 \mathrm{kHz}$. Figure 5 displays the transition frequencies of the $\tan \delta$ peaks for the epoxy and MWNT-epoxy composites with concentrations of 0.05 , $0.1,0.15,0.5$, and $2 \mathrm{wt} \%$ MWNTs. The transition loss peak of pure epoxy is at the low frequency of $29 \mathrm{kHz}$. As the MWNT content is gradually increased, the transition loss peak moves initially to higher frequencies for the 0.05 and the optimum dispersed $0.1 \mathrm{wt} \%$ MWNT-epoxy samples, it then moves back to lower frequencies for 0.15 and $0.5 \mathrm{wt} \%$ MWNTepoxy samples due to the insufficient MWNT dispersion, and finally it moves to higher frequencies again when the MWNT content is increased to $2 \mathrm{wt} \%$.

DEA is concerned with the determination of the complex dielectric constant, which consists of the real part, $\varepsilon^{\prime}$, which is the dielectric permittivity under $\mathrm{AC}$, and the imaginary part, $\varepsilon^{\prime \prime}$, which is the dielectric loss factor:

$$
\varepsilon^{*}=\varepsilon^{\prime}-i \varepsilon^{\prime \prime} .
$$

In this case, the dielectric loss tangent is given by the relation:

$$
\tan \delta=\frac{\varepsilon^{\prime \prime}}{\varepsilon^{\prime}} .
$$

Figure 6 presents the $\tan \delta$ spectrum from the DEA analysis in the range of $0.1 \mathrm{~Hz}$ to $1 \mathrm{MHz}$. The epoxy sample has a high transition peak at very low frequency below $0.1 \mathrm{~Hz}$, various small transition peaks in the frequency range of 10 to $100 \mathrm{~Hz}$ and a loss peak at high frequencies, starting with a peak below $100 \mathrm{kHz}$, and increasing loss at frequencies $1 \mathrm{MHz}$ and above. The addition of $0.1 \mathrm{wt} \%$ MWNTs eliminates the various transition peaks between $1 \mathrm{~Hz}$ and $10 \mathrm{kHz}$, due to the good conductivity of the MWNT network; however, there is a dielectric loss peak at $270 \mathrm{kHz}$, which is consistent with the results of the impedance analysis (Figure 4). Figure 7 presents a plot of the DEA transition peaks frequencies as a function of the MWNT concentration in the composite specimens. In general, specimens with MWNT concentrations above $0.1 \mathrm{wt} \%$ exhibit transition peaks below $270 \mathrm{kHz}$, due to the presence of MWNT agglomerates which are detrimental to MWNT network formation.

The next step is to determine all the dielectric and electromagnetic properties of the epoxy and the MWNTepoxy nanocomposites. Figure 8 shows the dielectric constant (real part) of the epoxy and the $0.1 \mathrm{wt} \%$ MWNT-epoxy nanocomposite as a function of frequency in the broadband $0.1 \mathrm{~Hz}$ to $1 \mathrm{MHz}$. The dielectric constant of the epoxy is fairly constant with frequency, displaying a small decrease as the frequency increases. The addition of $0.1 \mathrm{wt} \% \mathrm{MWNT}$ raises the dielectric constant from 3.6 for the pure epoxy to 78 for the MWNT-epoxy nanocomposite at low frequencies. That value of dielectric constant remains almost constant for the nanocomposite until about $10 \mathrm{kHz}$ and thereafter it decreases to a value of 26 at $1 \mathrm{MHz}$ (Figure 8(b)). The dielectric performance of the $0.1 \mathrm{wt} \%$ MWNT-epoxy nanocomposite in this study is much better than in previous reports [45] with high dielectric constant and long plateau versus frequency at very low MWNT content. Figure 9 presents the dependence of the dielectric constant at the low frequency of $0.1 \mathrm{~Hz}$ as a function of the MWNT concentration. It is clear that the $0.1 \mathrm{wt} \%$ MWNT-epoxy composite has the highest value of dielectric constant, whereas this value falls for MWNT concentrations higher than $0.1 \mathrm{wt} \%$ and lower than $2 \mathrm{wt} \%$ due to MWNT dispersion problems, and it rises again after $2 \mathrm{wt} \%$ MWNTs but much more slowly, to a value of 18 for $7 \mathrm{wt} \%$ MWNTs in epoxy.

The electrical conductivity, $\sigma$, of a material under AC is given by the equation:

$$
\sigma=\varepsilon_{o} \varepsilon^{\prime \prime} \omega
$$

Figure 10 presents the electrical conductivity of the epoxy and the $0.1 \mathrm{wt} \%$ MWNT-epoxy nanocomposite. The addition of $0.1 \mathrm{wt} \%$ MWNTs raises the electrical conductivity by about 2 orders of magnitude at very low frequencies $(0.1 \mathrm{~Hz})$ but by much more at higher frequencies, for example, by 4 orders of magnitude at $1 \mathrm{MHz}$. As the electromagnetic shielding capability of a material is proportional to its electrical conductivity, a higher increase of the electrical conductivity due to the addition of MWNTs at high frequencies is significant. Figure 11 presents the electrical conductivity of the epoxy and MWNT-epoxy composites at $1 \mathrm{MHz}$ as a function of the MWNT concentration. The specimen with $0.1 \mathrm{wt} \% \mathrm{MWNTs}$ has clearly the highest conductivity.

Electromagnetic shielding over the frequency range examined in this study is used in electronic and electrical packaging and in a variety of applications. The effectiveness of electromagnetic shielding, SE, comprises absorption loss and reflection loss, which are proportional to the product $\sigma \mu$ and the ratio $\sigma / \mu$, respectively, where $\mu$ is the magnetic permeability of the material [43]. These, in turn, are proportional to $L / R$ (absorption loss) and 1/RL (reflection loss), respectively. In this analysis, the calculations have been carried out for the best MWNT-epoxy nanocomposite at $0.1 \mathrm{wt} \%$ MWNTs and the pure epoxy. Figure 12 presents $L / R$ as a measure of the absorption loss: it seems that epoxy offers negligible absorption at all frequencies, which is expected due to its low conductivity; on the other hand, the $0.1 \mathrm{wt} \%$ MWNT-epoxy nanocomposite offers SE via absorption at low frequencies up to $2 \mathrm{kHz}$. Figure 13 presents $1 / \mathrm{RL}$ as a measure of the reflection loss: reflection loss rises at high frequencies for both materials due to the corresponding rise of their electrical conductivity (Figure 10). However, the $0.1 \mathrm{wt} \%$ MWNTepoxy nanocomposite offers better reflection shielding than the pure epoxy and this effectiveness rises at high frequencies. Hence, the 0.1 wt.\% MWNT-epoxy nanocomposite offers enhanced SE at low frequencies below $2 \mathrm{kHz}$ due to higher absorption loss and it also offers enhanced SE at high frequencies due to higher reflection loss.

\section{Conclusions}

A combination of dynamic characterisation techniques have been applied to MWNT-epoxy composites of different compositions and the pure epoxy, including DMA, DEA, and 
impedance spectroscopic analysis. The different techniques covered different frequency regions, sometimes overlapping. The dynamic impedance and the DEA techniques proved particularly useful at determining the quality of MWNT dispersion as the electrical properties depend specifically on the formation of MWNT network, whose conductivity rises as the number of MWNT paths increases. Large MWNT aggregates, on the other hand, offer few contact points between these aggregates and deplete the efficient MWNT network from much needed MWNT line-links. Both the DEA and the impedance spectroscopy demonstrated that the optimum MWNT concentration for best dispersion and best network formation was at $0.1 \mathrm{wt} \%$ MWNT. A small increase to $0.15 \mathrm{wt} \%$ yielded MWNT aggregates reducing dramatically the electrical conductivity of the composite (see Figure 11); further increase of the MWNT content up to $7 \mathrm{wt} \%$ increased the electrical conductivity a little but never to the optimum point at $0.1 \mathrm{wt} \%$ MWNTs. This is a very important conclusion proving that raising the MWNT content may be both expensive and detrimental to the properties of the composite; hence, an optimum composition should always be established which would apply to a certain material system and processing procedure and equipment. The Nyquist impedance plot (Figure 3) is most useful in establishing the homogeneity of a composite as it exhibits a single semicircle for homogeneous materials, two semicircles for dual conductive particle-size distribution, and one or more distorted or overlapping semicircles for a continuous particle size distribution.

DMA showed that the addition of $0.1 \mathrm{wt} . \%$ MWNTs in epoxy suppresses a transition $\tan \delta$ peak at $31 \mathrm{~Hz}$ and a loss modulus peak near $0.1 \mathrm{~Hz}$ as the CNT network stiffens the molecular structure of the material and seems to inhibit certain molecular transitions. The Nyquist plot from the impedance analysis revealed that $0.1 \mathrm{wt} . \%$ MWNTs drastically reduces the diameter of the Nyquist semicircle and it even leads to capacitor behaviour at frequencies below $20 \mathrm{kHz}$. The DEA spectrometric analysis yielded the conclusion that this very low loading of MWNTs suppresses any dielectric loss peaks in the band of $0.1 \mathrm{~Hz}$ to $10 \mathrm{kHz}$ and leaves the dielectric loss peak at $270 \mathrm{kHz}$, which is consistent with the results of the impedance analysis (LCR).

Finally, material properties were determined from the DMA, impedance analysis, and DEA. The addition of $0.1 \mathrm{wt} . \%$ MWNTs raised the elastic shear modulus by $12 \%$. However, by adding $0.1 \mathrm{wt} . \%$ MWNTs the dielectric constant was raised much more, from 3.7 (epoxy) to 78 (MWNTepoxy nanocomposite) at low frequencies: the latter remained approximately constant up to about $10 \mathrm{kHz}$ and it decreased thereafter to a value of 26 at $1 \mathrm{MHz}$. The electrical conductivity increased with frequency for both materials but much faster for the MWNT-epoxy nanocomposite. Hence, the addition of $0.1 \mathrm{wt} . \%$ MWNTs brought an increase in the electrical conductivity of about 2 orders of magnitude at low frequencies $(0.1 \mathrm{~Hz})$ and of 4 orders of magnitude at $1 \mathrm{MHz}$. By adding $0.1 \mathrm{wt}$. \% MWNTs, the effectiveness of electromagnetic shielding (SE) was dramatically increased at low-to-medium frequencies $(0.1 \mathrm{~Hz}$ to $2 \mathrm{kHz})$ due to a corresponding increase in the absorption loss whereas a large increase in SE was also achieved at high frequencies for the nanocomposite due to the corresponding increase in the reflection loss. As a result, the $0.1 \mathrm{wt} . \%$ MWNTepoxy nanocomposite switches electromagnetic shielding behaviour from a very effective absorber at low frequencies below $2 \mathrm{kHz}$ to an effective reflector at high frequencies.

\section{Acknowledgments}

The authors would like to gratefully acknowledge the funding of IeMRC/EPSRC for this study and the partial funding of the European Community FP7 Project AUTOSUPERCAP for this paper.

\section{References}

[1] J. Njuguna, K. Pielichowski, and J. R. Alcock, "Epoxy-based fibre reinforced nanocomposites," Advanced Engineering Materials, vol. 9, no. 10, pp. 835-847, 2007.

[2] D.-K. Choi, S.-H. Jin, and D.-S. Lee, "Preparation and properties of pyrene-modified multi-walled carbon nanotube/epoxy resin nanocomposites," Macromolecular Symposia, vol. 264, no. 1, pp. 100-106, 2008.

[3] K. S. Seo and D. S. Kim, "Curing behavior and structure of an epoxy/clay nanocomposite system," Polymer Engineering and Science, vol. 46, no. 9, pp. 1318-1325, 2006.

[4] H. Lu, H. Shen, Z. Song, K. S. Shing, W. Tao, and S. Nutt, "Rodlike silicate-epoxy nanocomposites," Macromolecular Rapid Communications, vol. 26, no. 18, pp. 1445-1450, 2005.

[5] A. Hartwing, M. Sebald, D. Putz, and L. Aberle, "Preparation, characterisation and properties of nanocomposites based on epoxy resins - an overview," Macromolecular Symposia, vol. 221, pp. 127-136, 2005.

[6] C. M. Manjunatha, A. C. Taylor, and A. J. Kinloch, "The tensile fatigue behavior of a GFRP composite with rubber particle modified Epoxy matrix," Journal of Materials Science, vol. 44, pp. 342-345, 2009.

[7] J. Choi, A. F. Yee, and R. M. Laine, "Toughening of cubic silsesquioxane epoxy nanocomposites using core-shell rubber particles: a three-component hybrid system," Macromolecules, vol. 37, no. 9, pp. 3267-3276, 2004.

[8] K.-C. Cheng, C.-M. Lin, S.-F. Wang, S. T. Lin, and C. F. Yang, "Dielectric properties of epoxy resin-barium titanate composites at high frequency," Materials Letters, vol. 61, no. 3, pp. 757-760, 2007.

[9] C. Dispenza, J. T. Carter, P. T. McGrail, and G. Spadaro, "Cure behaviour of epoxy matrices for carbon fibre composites," Polymer International, vol. 48, pp. 1229-1236, 1999.

[10] M. Q. Zhang, M. Z. Rong, H. B. Zhang, and K. Friedrich, "Mechanical properties of low nano-silica filled high density polyethylene composites," Polymer Engineering and Science, vol. 43, no. 2, pp. 490-500, 2003.

[11] S. Iijima, "Helical microtubules of graphitic carbon," Nature, vol. 354, no. 6348, pp. 56-58, 1991.

[12] S. Li, Y. Qin, J. Shi, Z.-X. Guo, Y. Li, and D. Zhu, "Electrical properties of soluble carbon nanotube/polymer composite films," Chemistry of Materials, vol. 17, pp. 130-135, 2005.

[13] H. Dai, "Carbon nanotubes: synthesis, integration, and properties," Accounts of Chemical Research, vol. 35, pp. 1035-1044, 2002. 
[14] R. H. Baughman, A. A. Zakhidov, and W. A. De Heer, "Carbon nanotubes-the route toward applications," Science, vol. 297, no. 5582, pp. 787-792, 2002.

[15] T. Shimizu, H. Abe, A. Ando, Y. Nakayama, and H. Tokumoto, "Electrical conductivity measurements of a multi-walled carbon nanotube," Surface and Interface Analysis, vol. 37, no. 2, pp. 204207, 2005.

[16] J. Hone, Encyclopedia of Nanoscience and Nanothechnology, 2004.

[17] T. Arie, N. Yoshida, S. Akita, and Y. Nakayam, "Quantitative analysis of the magnetic properties of a carbon nanotube probe in magnetic force Microscopy," Journal of Physics D, vol. 34, pp. L43-L45, 2001.

[18] C. Q. Sun, H. L. Bai, B. K. Tay, S. Li, and E. Y. Jiang, "Dimension, strength, and chemical and thermal stability of a single $\mathrm{C}-\mathrm{C}$ bond in carbon nanotubes," Journal of Physical Chemistry B, vol. 107, no. 31, pp. 7544-7546, 2003.

[19] W. Chen, X. Tao, and Y. Liu, "Carbon nanotube-reinforced polyurethane composite fibers," Composites Science and Technology, vol. 66, no. 15, pp. 3029-3034, 2006.

[20] G. Jell, R. Verdejo, L. Safinia, M. S. P. Shaffer, M. M. Stevens, and A. Bismarck, "Carbon nanotube-enhanced polyurethane scaffolds fabricated by thermally induced phase separation," Journal of Materials Chemistry, vol. 18, no. 16, pp. 1865-1872, 2008.

[21] R. Song, D. Yang, and L. He, "Preparation of Semi-aromatic polyamide(PA)/multi-wall carbon nanotube (MWCNT) composites and its dynamic mechanical properties," Journal of Materials Science, vol. 43, no. 4, pp. 1205-1213, 2008.

[22] B. Schartel, P. Pötschke, U. Knoll, and M. Abdel-Goad, "Fire behaviour of polyamide 6/multiwall carbon nanotube nanocomposites," European Polymer Journal, vol. 41, no. 5, pp. 1061-1070, 2005.

[23] X. Zhang, J. Zhang, R. Wang, T. Zhu, and Z. Liu, "Surfactantdirected polypyrrole/CNT nanocables: synthesis, characterization, and enhanced electrical properties," ChemPhysChem, vol. 5, no. 7, pp. 998-1002, 2004.

[24] Y. Long, Z. Chen, X. Zhang, J. Zhang, and Z. Liu, "Electrical properties of multi-walled carbon nanotube/polypyrrole nanocables: percolation-dominated conductivity," Journal of Physics D, vol. 37, no. 14, pp. 1965-1969, 2004.

[25] F. Wang, H. Gu, and T. M. Swager, "Carbon nanotube/polythiophene chemiresistive sensors for chemical warfare agents," Journal of the American Chemical Society, vol. 130, no. 16, pp. 5392-5393, 2008.

[26] M. R. Karim, J. H. Yeum, M. S. Lee, and K. T. Lim, "Synthesis of conducting polythiophene composites with multi-walled carbon nanotube by the $\gamma$-radiolysis polymerization method," Materials Chemistry and Physics, vol. 112, no. 3, pp. 779-782, 2008.

[27] S.-M. Yuen, C.-C. M. Ma, C.-C. Teng, H. H. O. Wu, H.C. Kuan, and C.-L. Chiang, "Molecular motion, morphology, and thermal properties of multiwall carbon nanotube/polysilsesquioxane composite," Journal of Polymer Science B, vol. 46, no. 5, pp. 472-482, 2008.

[28] S.-M. Yuen and C.-C. M. Ma, "Morphological, electrical, and mechanical properties of multiwall carbon nanotube/polysilsesquioxane composite," Journal of Applied Polymer Science, vol. 109, no. 3, pp. 2000-2007, 2008.

[29] A. A. Koval'chuk, A. N. Shchegolikhin, V. G. Shevchenko, P. M. Nedorezova, A. N. Klyamkina, and A. M. Aladyshev, "Synthesis and properties of polypropylene/multiwall carbon nanotube composites," Macromolecules, vol. 41, no. 9, pp. 3149-3156, 2008.

[30] M. V. Jose, D. Dean, J. Tyner, G. Price, and E. Nyairo, "Polypropylene/carbon nanotube nanocomposite fibers: processmorphology-property relationships," Journal of Applied Polymer Science, vol. 103, no. 6, pp. 3844-3850, 2007.

[31] S.-M. Yuen, M. Chen-Chi, H.-H. Wu et al., "Preparation and thermal, electrical, and morphological properties of multiwalled carbon nanotube and epoxy composites," Journal of Applied Polymer Science, vol. 103, no. 2, pp. 1272-1278, 2007.

[32] S. Tian and X. Wang, "Fabrication and performances of epoxy/ multi-walled carbon nanotubes/piezoelectric ceramic composites as rigid piezo-damping materials," Journal of Materials Science, vol. 43, no. 14, pp. 4979-4987, 2008.

[33] J. Njuguna and K. Pielichowski, "Polymer nanocomposites for aerospace applications: properties," Advanced Engineering Materials, vol. 5, no. 11, pp. 769-778, 2003.

[34] J. Wang, Y. Xu, X. Chen, and X. Sun, "Capacitance properties of single wall carbon nanotube/polypyrrole composite films," Composites Science and Technology, vol. 67, no. 14, pp. 29812985, 2007.

[35] M. H. G. Wichmann, S. T. Buschhorn, L. Böger, R. Adelung, and K. Schulte, "Direction sensitive bending sensors based on multiwall carbon nanotube/epoxy nanocomposites," Nanotechnology, vol. 19, no. 47, Article ID 475503, 2008.

[36] Y.-H. Yun, V. Shanov, M. J. Schulz et al., "Development of novel single-wall carbon nanotube-epoxy composite ply actuators," Smart Materials and Structures, vol. 14, no. 6, pp. 1526-1532, 2005.

[37] M. Baibarac and P. Gómez-Romero, "Nanocomposites based on conducting polymers and carbon nanotubes: from fancy materials to functional applications," Journal of Nanoscience and Nanotechnology, vol. 6, no. 2, pp. 289-302, 2006.

[38] G. Rebord, N. Hansrisuk, B. Lindsay, C. Lekakou, G. T. Reed, and J. F. Watts, "Electrofunctional polymer nanocomposites," in Proceedings of the 2nd Electronics Systemintegration Technology Conference (ESTC '08), pp. 1401-1405, Greenwich, UK, September 2008 .

[39] C. Lekakou, I. Kontodimopoulos, A. K. Murugesh et al., "Processability studies of silica-thermoset polymer matrix nanocomposites," Polymer Engineering and Science, vol. 48, no. 2, pp. 216-222, 2008.

[40] R. Schueler, J. Petermannz, K. Schulte, and H.-P. Wentzel, "Percolation in carbon black filled epoxy resin," Macromolecular Symposia, vol. 104, pp. 261-268, 1996.

[41] J. K. W. Sandler, J. E. Kirk, I. A. Kinloch, M. S. P. Shaffer, and A. H. Windle, "Ultra-low electrical percolation threshold in carbon-nanotube-epoxy composites," Polymer, vol. 44, no. 19, pp. 5893-5899, 2003.

[42] L. Chang, K. Friedrich, L. Ye, and P. Toro, "Evaluation and visualisation of the percolating networks in multi-wall carbon/epoxy composites," Journal of Materials Science, vol. 44, pp. 4003-4012, 2009.

[43] C.-S. Zhang, Q.-Q. Ni, S.-Y. Fu, and K. Kurashiki, "Electromagnetic interference shielding effect of nanocomposites with carbon nanotube and shape memory polymer," Composites Science and Technology, vol. 67, no. 14, pp. 2973-2980, 2007.

[44] N. Li, Y. Huang, F. Du et al., "Electromagnetic Interference (EMI) shielding of single-walled carbon nanotube Epoxy composites," Nano Letters, vol. 6, no. 6, pp. 1141-1145, 2006. 
[45] M. K. Yeh, N. H. Tai, G. C. Ling, and C. Y. Huang, "Electromagnetic shielding of multi-walled carbon nanotube/epoxy nanocomposites," Advanced Materials Research, vol. 47-50, pp. 475-478, 2008.

[46] X. Guo, D. Yu, Y. Gao, Q. Li, W. Wan, and Z. Gao, "Dielectric properties of filled carbon nanotubes/epoxy composites with high dielectric constant," in Proceedings of the 1st IEEE International Conference on Nano Micro Engineered and Molecular Systems, pp. 295-298, Zhuhai, China, January 2006.

[47] R. Hollertz, S. Chatterjee, H. Gutmann, T. Geiger, F. A. Nüesch, and B. T. T. Chu, "Improvement of toughness and electrical properties of epoxy composites with carbon nanotubes prepared by industrially relevant processes," Nanotechnology, vol. 22, no. 12, Article ID 125702, 2011.

[48] L. Liu, K. C. Etika, K. S. Liao, L. A. Hess, D. E. Bergbreiter, and J. C. Grunlan, "Comparison of covalently and noncovalently functionalized carbon nanotubes in epoxy," Macromolecular Rapid Communications, vol. 30, no. 8, pp. 627-632, 2009.

[49] A. V. Gromov, N. Gray, P. A. Szilagyi, and E. E. B. Campbell, "Direct grafting of carbon nanotubes with ethylenediamine," Journal of Materials Chemistry, vol. 22, pp. 21242-21248, 2012.

[50] N. B. T. Asari-Mansor, J.-P. Tessonnier, A. Rinaldi, S. Reiche, and M. G. Kutty, "Chemically modified multi-walled carbon nanotubes (MWCNTs) with anchored acidic groups," Sains Malaysiana, vol. 41, no. 5, pp. 603-609, 2012.

[51] A. K. Murugesh, A. Uthayanan, and C. Lekakou, "Electrophoresis and orientation of multiple wall carbon nanotubes in polymer solution," Applied Physics A, vol.100, no. 1, pp. 135-144, 2010. 

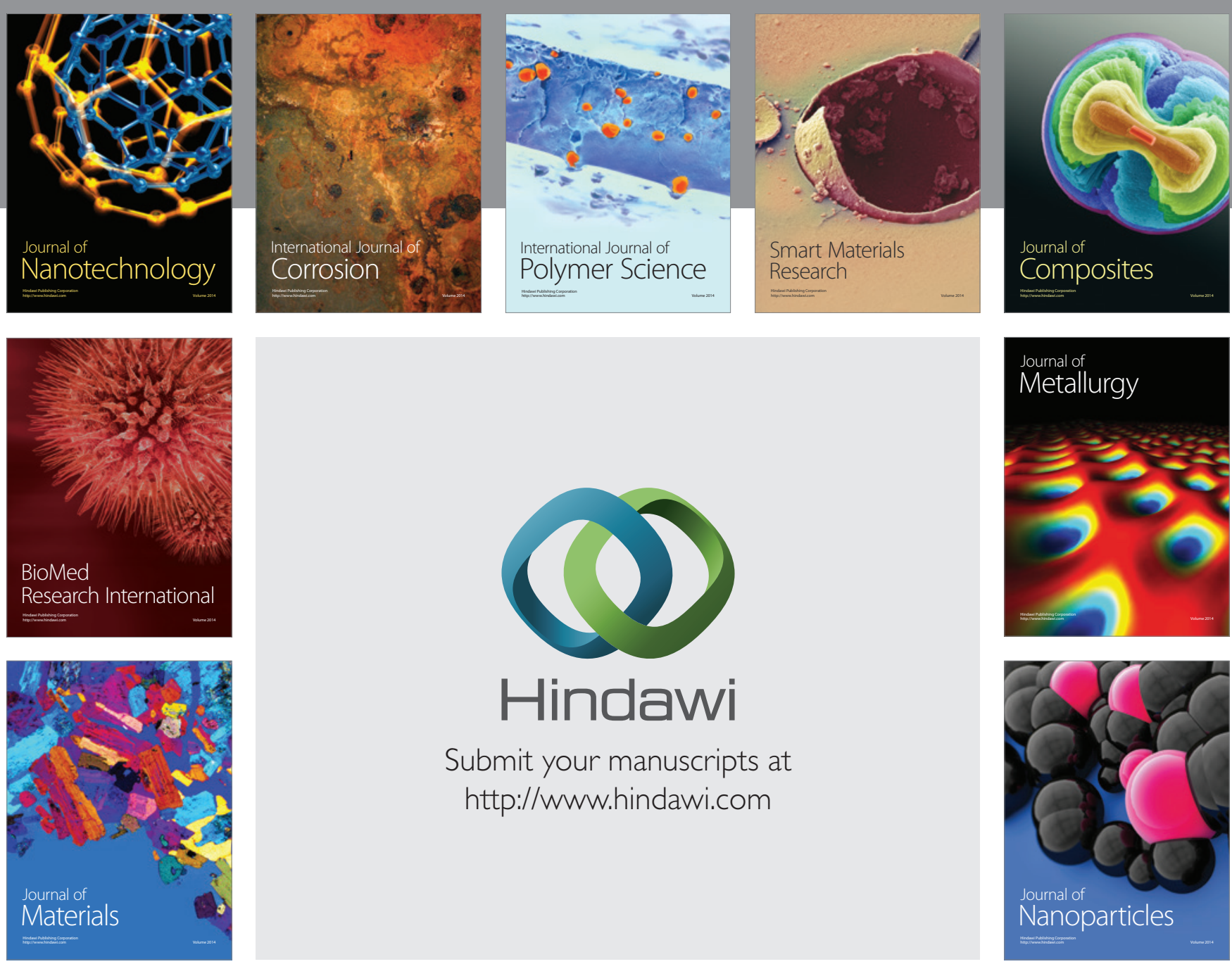

Submit your manuscripts at http://www.hindawi.com
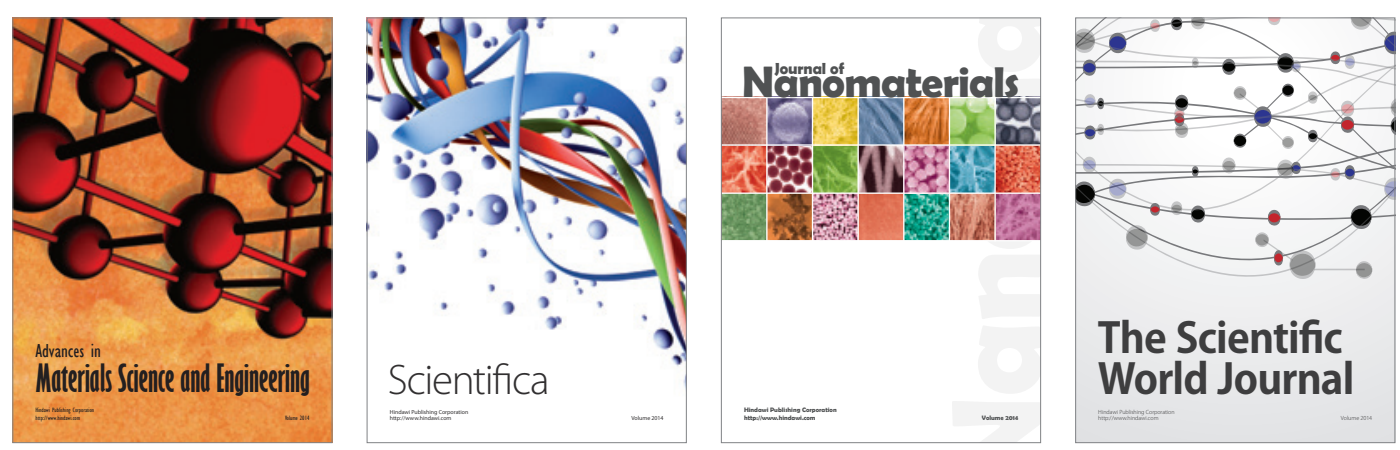

\section{The Scientific World Journal}
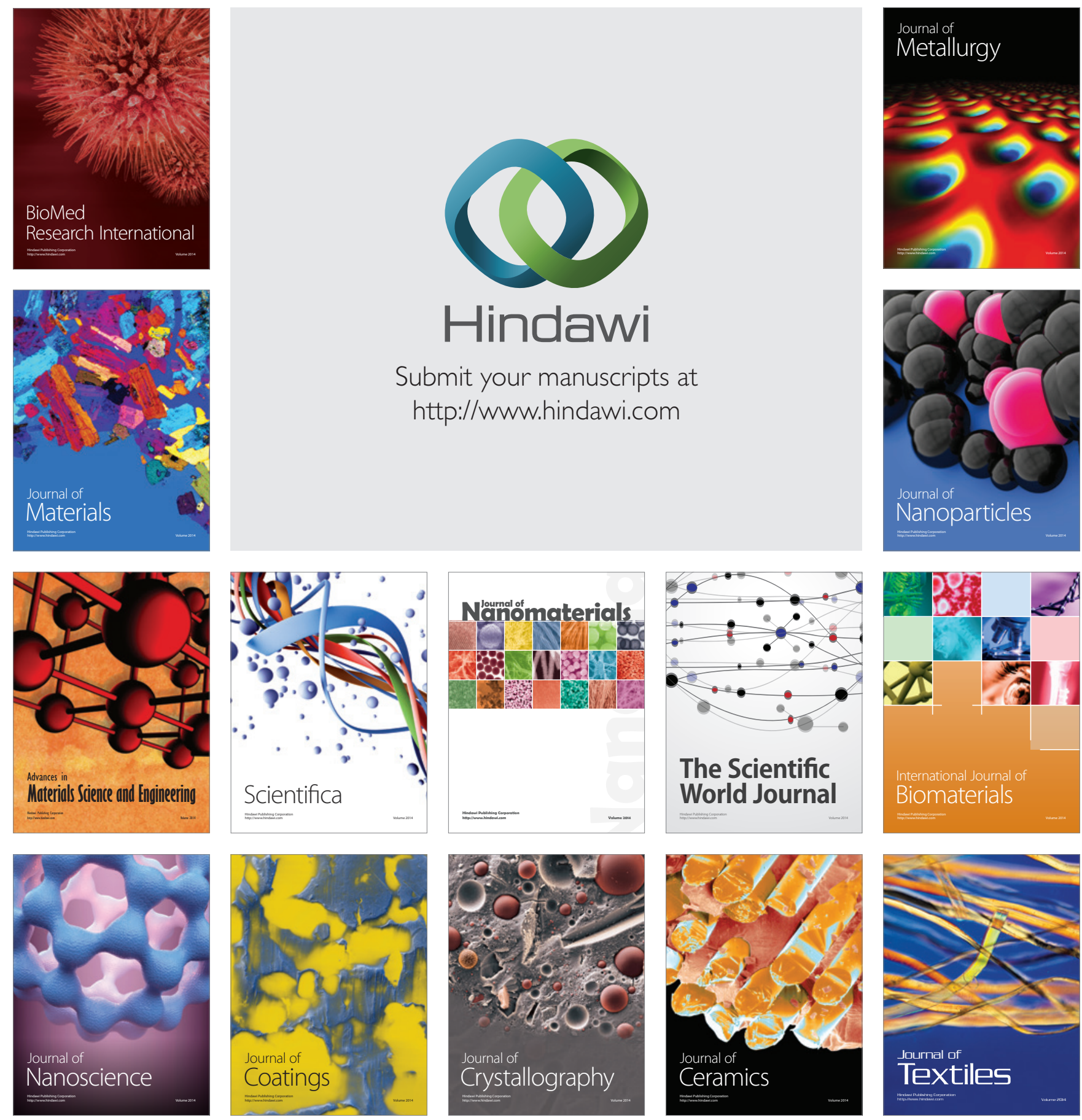